ISSN No. 0974-035X

An indexed refereed \& peer-reviewed journal of higher education

Towards Excellence

UGC-HUMAN RESOURCE DEVELOPMENT CENTRE

Gujarat University, Ahmedabad-380009, Gujarat, India

\title{
DEVELOPING COMFORTABLE LEARNING ZONE FOR TRIBAL STUDENTS IN JHARKHAND THROUGH MULTICULTURAL TEACHING
}

\section{Dr. Sushil Kumar Tiwari}

\begin{abstract}
India is a country of diverse culture where the people of various religions, faiths, castes, tribes, classes, languages etc. live together. Multiculturalism is inherent in Indian society and there is a long history of unity in diversity. Indian classrooms too, delineate tremendous diversity. Similar to the worldview of multicultural formal education, no Indian classroom is monocultural. At some places, like in tribal dominated state Jharkhand, it is a major concern and liberates enough ground to redesign teaching. There is a general misconception that multicultural teaching is the need of minority groups of the classroom. Tribal students are dominant in most of the schools of Jharkhand as far as number is concerned. But even then, many of them are not comfortable to learn equally with others. Multicultural teaching provides comfortable zone of learning for them. Present paper entails about the multicultural teaching with adequate representation of tribes of Jharkhand in content, pedagogy and classroom environment. The research carried out to explore the scope of representation to develop multicultural plan and methodology, combined to term as multicultural teaching. The multicultural lesson plan and certain multicultural interventions has been developed and compared with conventional teaching for the required frame of reference.
\end{abstract}

Keywords: Multiculturalism, Indian classrooms, tribal dominated, multicultural teaching, comfortable zone of learning. 


\section{Introduction}

Formal education and teaching-learning process has passed a long way. Till now this journey is going on with new challenges and to mitigate those, formal education is incorporating innovative, advanced and modern practices with smart classrooms. It is a fact, that promoting equality or equal opportunities to all in education is the ultimate goal. Constitutional provisions are also there but how to realize them in practice is still an inapprehensible task. Earlier approaches were focused to the extent "not to ignore any one in the classroom" but multicultural teaching is beyond than that. Specifying the multicultural teaching strategy to realize the holistic goals of multiculturalism is the major concern of teaching. It is possible through developing multicultural lesson plan and using multicultural pedagogical interventions.

It is pointed out by Hoopes, (1979), "individuals who have competencies in and can operate successfully in two or more different cultures are bicultural or multicultural. Multicultural persons feel comfortable and communicate effectively" (p.21). The students of a particular culture may belong to unrepresented culture in a classroom and that's why in the classroom group dynamics, they may feel uncomfortable. It may affect their learning. Hence, that should be compensated by their representation in that particular environment.

Present study was not confined to the cultural differences of the students of particular classroom, but it was about their overall perspective to deal with diversity. It was the major concern that the classroom transaction should be aimed at 'respect for diversity', no matter whether the class is diversified or not. They were involved in learning to recognize and respect even those cultures that were not the part and parcel of their classroom or even of their community and society.

\section{Need and Relevance}

In the tribal dominated state like Jharkhand tribal students are more than the non-tribal students in most of the classrooms but the concerned book and course material do not have such representation of the 
tribal culture. Present Indian central government is willing to change this through the proposed new education policy. The draft of the policy is in public domain and it has reiterated time and again about the shift towards adequate cultural ad local inputs.

Tribal people in India celebrate many such festivals that are more susceptible to the issues like environmental and natural preservation, women empowerment, coordination, harmony etc. These characteristics of tribal culture and some other local inputs, examples and issues from other indigenous cultures are utilized to develop multicultural lesson plans. Through these dimensions to shift the students from unaware uncomfortable zone to their proximal multicultural comfortable zone of learning. Common issues of poverty, struggle and challenges were discussed with proper care so that students feel their recognition in the class in positive way.

Issues and challenges of tribal education is major concern for Jharkhand formal education system at secondary level. Since Jharkhand is a tribal dominated state, government secondary schools serve as the backbone of tribal education. Hence there is an urgent need to provide opportunities through multicultural teaching and to realise the goals of quality tribal education. Study is quite relevant to make the tribal students comfortable and to excel their potential level of learning through the planning and development of progressive classroom transactional process like multicultural teaching.

\section{Study Objective}

- To develop and plan multicultural classroom teaching for Science and Social Science at Secondary Level.

\section{Study Population and Sampling Technique}

The government secondary schools of East Singbhum District of Jharkhand were selected through random sampling technique. The selection of district was done through convenient sampling at first. Although the study was carried out in one district but due to similar curriculum of all the government schools running under Jharkhand Academic Council (JAC), Ranchi and teaching methodologies in all 
Towards Excellence: An Indexed, Refereed \& Peer Reviewed Journal of Higher Education / Dr. Sushil Kumar Tiwari / Page 311-323

the government schools are more or less same so the findings related to development and planning of multicultural teaching is applicable to all the secondary schools of Jharkhand.

\section{Literature Study}

Although the study in the field of multicultural education must be extended to indigenous and tribal groups even then they are not adequately explored, at least in India. The specific studies to design multicultural teaching for tribal students at classroom level are rare. Rightly pointed out by Roy (2011) that "multiculturalism, however, assumed a new connotation in the context of growing awareness about indigenous tribal cultures and their conservation. Although Indian tradition of "cultural diversity"e and "unity in diversity" has received curious attentions."

Muthukumaraswamy, (2009) pointed out that "in a project serving 200 schools started in 2007 in the Indian state of Orissa for Indigenous tribal children from ten language groups, students are being taught through their mother tongues in the primary grades with materials collected from children, parents and teachers. Sixteen more languages were added in 2008". Orisaa is the adjacent state and due to sharing tribal values and culture the study has its relevance for Jharkhand tribal students. Demir \& Yurdakul (2015) studied about required multicultural education characteristics in curriculum design. The method applied for this study was phenomenological method. Content analysis method was used to analyse multicultural literatures. The findings were in the form of curriculum's elements as themes.

Studying in relation to the objective of the study, the following concepts are utmost important to discuss about the development and planning of multicultural classroom teaching:

\section{Multicultural Teacher}

The multifaceted role of the teacher is a fact. To personate this, teachers must be knowledgeable about the various strategies so that they make good coordination with the students of different cultures. It will make teaching process easier, flexible and leads to positive result. In the globalized world, teacher is facing so many challenges inside and outside the classroom. One among them is classroom diversity. 
Towards Excellence: An Indexed, Refereed \& Peer Reviewed Journal of Higher Education / Dr. Sushil Kumar Tiwari / Page 311-323

Multicultural teacher can tackle this challenge and may use the diversity as opportunity to realize ultimate goals of education. U.S. Commission on Civil Rights (1973, as cited in Gollnick \& Chinn, 1983, p.310) rightly remarked on teacher-student interaction as, "it is through this action that the school system makes its major impact upon the child. The way the teacher interacts with the student is a major determinant of the quality of education the child receives."

In the present study, a multicultural teacher is believed to have the sound knowledge of nature, objective and concept of multicultural education and multicultural strategies to justify with the students of diversified cultures. The investigator was working on multicultural education, understanding the role of multicultural teacher, developing lesson plans and selecting appropriate strategies during the research work, it was obvious to incarnate himself as multicultural teacher for the study.

Quite broad aspect is there, to say when the classroom recognizes and respects the diversified cultures beyond the four walls of classroom and which exist in outer world. Actually, it is to prepare for the ultimate diverse nature irrespective of the type of the diversity, its origin and background. Banks (1998) clarified about the concept he's developed called "the five dimensions of multicultural education." in an interview. To the question, "Why is multiculturalism so important?" he responded comprehensively that "we must learn to accept and get along with all cultures, races, and religions in order to become productive citizens of the world. It is our job as teachers to prepare our students for the real world [i.e. multicultural]."

\section{Multicultural Classroom}

The world today is multicultural one. Classrooms need to prepare the students for the present era. Whether the classroom constitutes the cultural diversity or not, the multicultural teaching is always a best choice. In the age of globalization, even many closed societies are having more or less diversity in their classrooms. Multicultural teaching can tackle the diversity of the classroom in such a way that the diversity may be the opportunity to learn effectively and to celebrate the differences respectfully. 
Towards Excellence: An Indexed, Refereed \& Peer Reviewed Journal of Higher Education / Dr. Sushil Kumar Tiwari / Page 311-323

There should be equality in classroom treatment for all the students of the classroom. The classroom is multicultural, if all the students of diverse backgrounds fill respected encouraged sharing their views and a sense of pride for the culture they belong too. It may be the basis to run the multicultural classrooms, however too narrow to justify multicultural classroom.

\section{Multicultural Lesson Plan}

The structure of the classroom was a concern of the multicultural lesson plan however the plan had the scope to learn sharing, cooperating, collaborating and other multicultural practices at its adequate level; prepared particularly for the present study. Earlier to the planning phase the nature of the learners was explored through an informal interaction and a sort of rapport was established. The systemic steps of multicultural plan were developed by the researcher to impart the course content through multiple multicultural pedagogical interventions. As far as possible more and more grouping, sharing, accommodations, cooperative and collaborative techniques were used to incorporate all the students of

varied cultures. The lesson plan of the taught chapters includes examples related to the culture of diversified groups, and different cultures of the country with the main subject matter, so that children correlate their knowledge with their own culture. While teaching the chapters through multicultural lesson plans, students had the opportunity to express ideas and realized their peer thoughts related to their own culture as well as other's culture also.

\section{Multicultural Teaching}

A teacher can follow the principles set by any particular model or theory of multicultural education in a formal classroom that may be referred as multicultural teaching. This is just like a tool in the hand of a teacher to mold the classroom environment as friendly as possible for all the learners. Multicultural education model proposed by Banks (2003) has been adopted in the present study and referred as multicultural teaching. 
Towards Excellence: An Indexed, Refereed \& Peer Reviewed Journal of Higher Education / Dr. Sushil Kumar Tiwari / Page 311-323

In the present study the multicultural teaching is conceived as adaptation of 'five-dimensional model of multicultural education' in classroom situation. So here multicultural teaching is defined as having the following dimensions: "content integration, knowledge construction, equity pedagogy, prejudice reduction and empowering school culture and social structure.” (Banks, 1998)

Investigator had adopted the "five-dimensional model" of Banks (2003); cited in Banks \& Banks (2010); for the multicultural teaching. The model was given mainly in context of K-12 classes and hence found suitable for the present study. Various connotations adopted from the five dimensions are given as follows that were applied to develop multicultural lesson plans and used in classroom multicultural classroom processes at the ground level.

Five-dimensional multicultural education model proposed by Banks was adopted in the study to develop multicultural lesson plans and pedagogical interventions that was referred as multicultural teaching.

\section{Content Integration}

Content integration is the dimension of multicultural teaching in present study which includes explaining history and origin of the content, history in social science with the present names of the place and life sketch of scientists with his/her background and sharing effective social linkages; using local resources and discussing local issues and challenges wherever found suitable with the course content. The following integrations were remarkable:

- Local resources like uranium mines in Jadugora and Steel plant of Jamshedpur were integrated.

- History and origin of the content for example history of the atom, theory and models were explained.

- The issues of drug addiction and teenager suicides in Jamshedpur linking with the course contents were discussed. 
- Life sketch of scientists in case of science with his/her background and sharing effective social linkages like poverty if he/she had encountered.

- History in social science was explained with the present names of the place and also with the description of well-known local celebrations, festivals and/or hero of all the diverse cultural groups.

\section{Knowledge Construction}

Knowledge construction is the dimension of multicultural teaching in present study which includes constructing knowledge of students about both the content and diversity by discussing the known challenges, problematic situation and opportunities, Moving from microscopic features to the macroscopic models and theories, presenting sideline view of the content that may be opposite sometimes and then approaching towards the shared and correct view and discussing global issues from the local issues wherever found suitable with the course content. This dimension was materialized into multicultural teaching through following ways:

- Lessons were developed from microscopic features of atomic, particle and molecules to the macroscopic models and theories.

- Sideline view of the content were presented that may be opposite sometimes and then approaching towards the shared and correct view.

- Radioactivity and other pollution related issues from Jadugora mines and steel plant could be the problematic situation to construct knowledge.

- Global issues with the help of local culture were discussed; for example- Tribal festivals and rituals; for sensitizing to preserve forests, water and environment and to achieve the goals of sustainable development.

- Constructing knowledge of students by discussing the known challenges and opportunities; basically environmental; in relation to the particular content like in case of atoms and nucleus 
Towards Excellence: An Indexed, Refereed \& Peer Reviewed Journal of Higher Education / Dr. Sushil Kumar Tiwari / Page 311-323

the nuclear energy and atom bomb can be discussed at first, in case of acid and bases the acid rain and different usable products can be discussed at first.

\section{Equity Pedagogy}

Bank (1998) termed the multicultural pedagogy as "equity pedagogy" and explained as, "a variety of teaching styles that are consistent with the wide range of learning styles within various cultural and ethnic groups." The pedagogical practices in multicultural teaching delineate the framework to develop the democratic and global citizens with the notion of equity. Equity pedagogy is the dimension of multicultural teaching in present study that included following steps:

- Rapport with all but especially with the tribal students of the classroom was established to allow free expression.

- Grouping on caste, religion, racist or gender basis was avoided rather grouping was practiced with mixing up the diversified language including tribal languages like Mundari, Nagpuri, Kurmali, Ho, Santhali etc. and ability groups.

- Examples from diverse tribal cultures were cited for true inclusion. For example, asking students about the metals they are using in their houses; during the transaction of contents related to 'metal and non-metal' in chemistry.

- The focus from one tribal group to other tribal group and changing the way to teach like to eliminate gender bias asking questions equitably to girl students and also allowing them to suggest the solution on the concerned problems.

\section{Prejudice Reduction}

Prejudice reduction is the dimension of multicultural teaching in present study facilitates positive bonding and interaction, using classroom and teaching materials to maintain equality in classroom treatment. This dimension was incorporated as follows: 
- Posters, pictures, music, toys, dolls, books, and other materials, for example, showing tribal men and tribal women both are working outside the home in demonstrations were used.

- Teaching material showing the goodness of all cultures like images and festivals of tribal cultures to recognize them.

- Teaching material showing the goodness of all cultures like images and festivals of tribal cultures were used to recognize them.

- Equality in classroom treatment for all the students of the classroom was maintained in reward and punishment, availability of resources and in the language congruence.

- Cross cultural communication among students and between teacher and student should be positive as different tribal languages and dialects used by the students were respected.

\section{Empowering School Culture and Social Structure}

Empowering school culture and social structure is the dimension of multicultural teaching in present study which includes personal and social support for better performance in group activities. Following measures were taken to recognizing multiple level abilities and shifting the learners into a multicultural comfortable zone of learning:

- Continuous assessment and grading were carried out not only on perfect answer but also on helping others in perfect answer.

- "Multiple level abilities" were recognized in any form i.e. in sports and other co-curricular activities in classroom discussion.

- Preferring situation that allows learners to use personal techniques and ideas for better performance in group activities.

- Social behaviors and any other activities of discomfort of students were also noticed sand were avoided or positively modified at once.

-Banks \& Banks (2010) 
Towards Excellence: An Indexed, Refereed \& Peer Reviewed Journal of Higher Education / Dr. Sushil Kumar Tiwari / Page 311-323

Thus, model was materialized into plan and methods of teaching to shift the students in a multicultural comfortable zone of learning.

Conventional lesson plan was usual plan that is in practice and that ignores the local and cultural inputs in classroom transaction. Hence, comparable characteristics and steps are there to plan and develop multicultural teaching as presented in table 1.0:

Table 1.0 characteristics and steps of lesson plans

\begin{tabular}{|c|c|c|c|}
\hline no. & $\begin{array}{l}\text { Characteristics } \\
\text { and steps }\end{array}$ & Multicultural teaching & Conventional teaching \\
\hline 1 & Nature & $\begin{array}{l}\text { Learner specific-care and concern } \\
\text { to all learners }\end{array}$ & $\begin{array}{l}\text { Content specific-care to complete } \\
\text { syllabus }\end{array}$ \\
\hline 2 & Scope & $\begin{array}{l}\text { Learning to each and every learner } \\
\text { even to the suppressed groups of } \\
\text { learners }\end{array}$ & $\begin{array}{l}\text { Learning affected by cultural } \\
\text { differences, thus suppressed groups } \\
\text { may learn least }\end{array}$ \\
\hline 3 & Recognition & $\begin{array}{l}\text { All the learners of diversified } \\
\text { culture including tribal culture }\end{array}$ & $\begin{array}{l}\text { Learners more active will be } \\
\text { recognized more }\end{array}$ \\
\hline 4 & $\begin{array}{l}\text { Steps } \\
\text { teaching } \\
\text { i) }\end{array}$ & $\begin{array}{l}\text { Formulating multicultural } \\
\text { objectives with instructional } \\
\text { objectives for the lesson. }\end{array}$ & $\begin{array}{l}\text { Formulating instructional objectives } \\
\text { and not the multicultural objectives } \\
\text { for the lesson. }\end{array}$ \\
\hline & ii) & $\begin{array}{l}\text { Introducing the lessons involving } \\
\text { students through question-answer } \\
\text { and asking questions from } \\
\text { previous knowledge }\end{array}$ & $\begin{array}{l}\text { Introducing the lesson involving } \\
\text { students through question-answer } \\
\text { and asking questions from previous } \\
\text { knowledge }\end{array}$ \\
\hline
\end{tabular}


Towards Excellence: An Indexed, Refereed \& Peer Reviewed Journal of Higher Education / Dr. Sushil Kumar Tiwari / Page 311-323

\begin{tabular}{|c|c|c|c|}
\hline & iii) & $\begin{array}{l}\text { Presentation with multicultural } \\
\text { dimensions with the usual } \\
\text { teaching points }\end{array}$ & $\begin{array}{l}\text { Presentation with only teaching } \\
\text { points of the contents }\end{array}$ \\
\hline & iv) & $\begin{array}{l}\text { Using teaching materials from the } \\
\text { diverse culture like from tribal, } \\
\text { rural, class based etc. (Whenever } \\
\text { found appropriate for the lesson to } \\
\text { be taught). }\end{array}$ & $\begin{array}{l}\text { Usual teaching materials mainly as } \\
\text { given in the book }\end{array}$ \\
\hline & v) & $\begin{array}{l}\text { Recapitulating the lesson } \\
\text { involving the students through } \\
\text { question-answer }\end{array}$ & $\begin{array}{l}\text { Recapitulating the lesson involving } \\
\text { the students through question- } \\
\text { answer }\end{array}$ \\
\hline 5 & $\begin{array}{l}\text { Examples to be } \\
\text { given }\end{array}$ & $\begin{array}{l}\text { From the diversified cultures and } \\
\text { multiple examples from } \\
\text { surroundings }\end{array}$ & Usual examples from content \\
\hline
\end{tabular}

\section{Study Findings and Conclusion}

Development and planning of multicultural teaching of science and social science is based on integration of contents, construction of knowledge, pedagogical interventions for equity, reduction of prejudices, empowering the classroom climate and school culture. The multicultural teaching includes supportive teacher behaviors; using accommodation, grouping, cooperative and collaborative teaching learning methods. Multicultural teaching eliminates the biasness and discomforts of learning in the classroom caused by the tribal student's different cultural identity on the basis of ethnicity, language, variable ability groups etc. Finally, it is important to know 'how to learn' with 'what to learn' and to incorporate multicultural teaching for quality tribal education in Jharkhand. 


\section{Works cited}

Banks, J A. and C A. Banks. Multicultural Education Issues and Perspectives. Multicultural Education (7th ed.). New Jercy: Wiley \& Sons, 2010.

Banks, J. A. Multiculturalism’s Five Dimensions. NEA Today Online, 1-4. 1, 1998.

Gollnick, D. M., \& P. C. Chin. Multicultural Education in a Pluralistic Society. St. Louis: Mosby, 1983.

Muthukumaraswamy, M.D. Multilingual education. Indian Folklife Serial, 32, 1-24. National Folklore Support Centre, Chennai, India, 2009. Web.

$<$ http://indianfolklore.org/nfscpress $>$

Roy, B. Understanding India's sociological diversity, unity in diversity and caste system in contextualizing a global conservation model. International Journal of Sociology and Anthropology Vol. 3(12), pp. 440-451, 2011. Web: March 17, 2018 $<$ http://www.academicjournals.org/journal/IJSA/article-full-text-pdf/BB9AB793171>

\section{Dr. Sushil Kumar Tiwari \\ https://orcid.org/0000-0003-3718-9487 \\ Associate Professor, PG Department, Faculty of Education, Jamshedpur Women's College, Jamshedpur Mail id: education.sushil@gmail.com Mob: 9835193084}

